\title{
Influence of Carbide Content on the Adhesion and Microscopic Hardness of Plasma Spray $\mathrm{Cr}_{3} \mathrm{C}_{2}-\mathrm{NiCr}$ Coating on 16Mn Steel
}

\author{
Dang Xuan Thao ${ }^{1, *}$, Hoang Van Got ${ }^{2}$, Nguyen Huu Phan', Pham Duc Cuong ${ }^{1}$ \\ ${ }^{1}$ Hanoi University of Industry, Vietnam \\ ${ }^{2}$ National Research Institute of Mechanical Engineering, Vietnam
}

Received October 9, 2019; Revised December 19, 2019; Accepted December 25, 2019

Copyright@2019 by authors, all rights reserved. Authors agree that this article remains permanently open access under the terms of the Creative Commons Attribution License 4.0 International License

\begin{abstract}
This paper presents a study on the effect of the $\mathrm{Cr}_{3} \mathrm{C}_{2}$ carbide content on the adhesion and micro-hardness of the $\mathrm{Cr}_{3} \mathrm{C}_{2}-\mathrm{NiCr}$ coatings coated on $16 \mathrm{Mn}$ alloy steel surface by using a plasma spraying technique. The results show that when the carbide content increases from $50 \%$ up to $80 \%$ by mass, the adhesion of the coating to the steel substrate is decreased about 3 times, from 43.58 MPa to $16.32 \mathrm{MPa}$. On the contrary, the micro-hardness of the coatings is increased about 1.7 times, from $411 \mathrm{HV}$ to $701 \mathrm{HV}$. The results of the study are the basis for technologists to choose the suitable proportion of $\mathrm{Cr}_{3} \mathrm{C}_{2}$ and $\mathrm{NiCr}$ of the coatings to apply in manufacturing as well as recovering mechanical parts.
\end{abstract}

Keywords $\mathrm{Cr}_{3} \mathrm{C}_{2}$-NiCr Coating, $16 \mathrm{Mn}$ Steel, Plasma Spraying, Adhesion, Hardness

\section{Introduction}

Thermal spray is often used to create a coating to protect the surface of a part or to enhance surface properties suitable for applications and working conditions. Depending on the purpose of use such as new manufacture or surface restoration of machine parts, it is possible to use spraying methods and select the appropriate type of coatings.

The $\mathrm{Cr}_{3} \mathrm{C}_{2}-\mathrm{NiCr}$ coating provides greater resistance to corrosion and oxidation and maintains high hardness, good mechanical properties, and wear resistance at high temperatures [7]. In addition to the above features, thermal expansion coefficient of $\mathrm{Cr}_{3} \mathrm{C}_{2}$ component also forms the basis of many high heat resistant alloys. This reduces stress through thermal expansion joints in the thermal cycle, and the erosion resistance of ceramic metal coatings increases along with the increase of chromium carbide in the powder before spraying. The coatings have recently been fabricated using thermal spray methods. To replace hard chromium coating, the $\mathrm{Cr}_{3} \mathrm{C}_{2}-\mathrm{NiCr}$ coating have attracted many researchers and users' attention. Espallargas et al investigated the corrosion resistance of the $\mathrm{Cr}_{3} \mathrm{C}_{2}-25 \mathrm{NiCr}$ coating fabricated by using High Velocity Oxygen Fuel (HVOF) method and the hard chromium coating. It is concluded that the HVOF-sprayed $\mathrm{Cr}_{3} \mathrm{C}_{2}-25 \mathrm{NiCr}$ coating was more resistant to corrosion than the hard chromium coating [2].

It is reported that mechanical properties of $\mathrm{Cr}_{3} \mathrm{C}_{2}-\mathrm{NiCr}$ coating is strongly depended on coating parameters. Suegama et al studied the effect of spraying parameters of the HVOF method on porosity and corrosion of the $\mathrm{Cr}_{3} \mathrm{C}_{2}-\mathrm{NiCr}$ coating. The authors revealed that the coating prepared with a gun movement speed of $1000 \mathrm{~mm} / \mathrm{s}$ and a spray distance of $200 \mathrm{~mm}$, gave the coating the lowest porosity $(\approx 1 \%)$ and high corrosion resistance in environments containing $\mathrm{H}_{2} \mathrm{SO}_{4}$ [3]. Li et al. reported the abrasion resistance of the $\mathrm{Cr}_{3} \mathrm{C}_{2}$-NiCr coating prepared by Atmospheric Plasma Spray (APS) technique with various gas mixtures [4]. The authors stated that the $\mathrm{Ar} / \mathrm{He}$ gas mixture provides higher abrasion resistance than the $\mathrm{Ar} / \mathrm{H}_{2}$ gas mixture. In other work, the thermal conductivity of the $\mathrm{Cr}_{3} \mathrm{C}_{2}-\mathrm{NiCr}$ coating fabricated by the APS method was considered. Their findings showed that the thermal conductivity of the coating increased when it was heat treated at $980^{\circ} \mathrm{C}$ [5]. In addition, Xie et al. studied the effect of heat treatment (using laser and plasma arc) on the structure and corrosive properties of $\mathrm{Cr}_{3} \mathrm{C}_{2}-\mathrm{NiCr}$ coating and found that the corrosion resistance of the coating treated by plasma arc is higher than that of laser treatment [6]. 
Table 1. The main chemical composition of $16 \mathrm{Mn}$ steel

\begin{tabular}{|c|c|c|c|c|c|c|c|c|}
\hline $\mathrm{C}(\%)$ & $\mathrm{Si}(\%)$ & $\mathrm{Mn}(\%)$ & $\mathrm{P}(\%)$ & $\mathrm{S}(\%)$ & $\mathrm{Cr}(\%)$ & $\mathrm{Cu}(\%)$ & $\mathrm{Ni}(\%)$ & $\mathrm{Mo}(\%)$ \\
\hline 0.17 & 0.27 & 1.31 & 0.015 & 0.02 & 0.04 & 0.02 & 0.01 & 0.01 \\
\hline
\end{tabular}

The mechanical properties of $\mathrm{Cr}_{3} \mathrm{C}_{2}$ - $\mathrm{NiCr}$ coating is also strongly depended on the variation of the coating components such as $\mathrm{Cr}_{3} \mathrm{C}_{2}$ and NiCr. The results of the studies show that $\mathrm{Cr}_{3} \mathrm{C}_{2}$ - $\mathrm{NiCr}$ coatings with different levels of carbide $\mathrm{Cr}_{3} \mathrm{C}_{2}$ have been widely used to prevent wear at high temperatures (up to $800-900^{\circ} \mathrm{C}$ ) and corrosion in environments with erosion agents [1]. The corrosion resistance of the $\mathrm{Cr}_{3} \mathrm{C}_{2}-\mathrm{NiCr}$ coating is related to the interaction between the carbide and $\mathrm{NiCr}$ components. In the mixture of $\mathrm{Cr}_{3} \mathrm{C}_{2}-\mathrm{NiCr}$ powder, the $\mathrm{NiCr}$ component has the role of increasing the cohesion between particles for the coating and cohesion; while the $\mathrm{Cr}_{3} \mathrm{C}_{2}$ component has the role of increasing the hardness and the load bearing capacity of the coating. This powder is suitable in manufacturing new parts/details or in restoring the wearand temperature-resistant parts.

In this study, we created $\mathrm{Cr}_{3} \mathrm{C}_{2}-\mathrm{NiCr}$ coatings on $16 \mathrm{Mn}$ steel by a plasma spraying technique. The content of carbide component $\left(\mathrm{Cr}_{3} \mathrm{C}_{2}\right)$ in the coating powder has been changed from $50 \%$ to $80 \%$ by mass. Adhesion $(\mathrm{K})$ and micro-hardness of the coating after fabrication were studied in order to evaluate the effects of the carbide content to such the properties.

\section{Experiment}

\subsection{Creation of Coating}

Coating sample: Cylindrical pin sample with dimensions as shown in Figure 1 is designed to evaluate the adhesion strength of the coating to the substrate. The sample is made of $16 \mathrm{Mn}$ steel with the chemical composition as shown in table 1 .

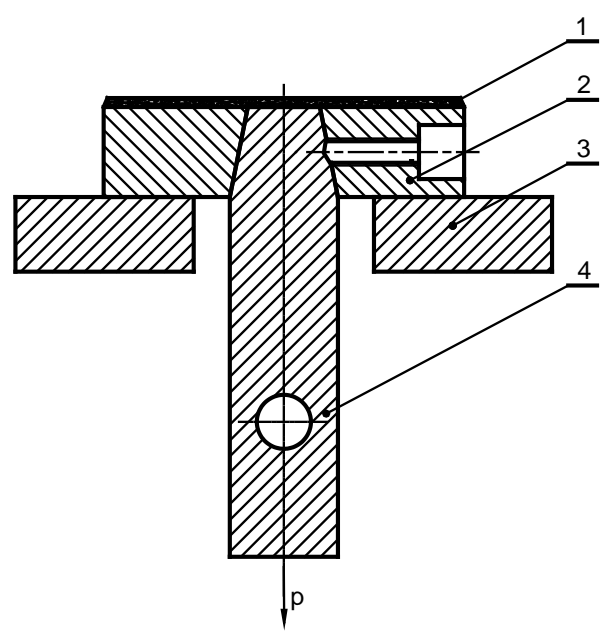

Figure 1. Drawing of sample: 1, Coating; 2, Latch disc; 3, Overriding plate; 4, Tensile latch
Coating material: $\mathrm{Cr}_{3} \mathrm{C}_{2}-\mathrm{NiCr}$ mixtured powder (Wisdom Consumables, China) is used for coating. $\mathrm{Cr}_{3} \mathrm{C}_{2}-\mathrm{NiCr}$ particles have an average diameter of $35 \pm 5$ $\mu \mathrm{m}$. The composition of carbide component in the powder is $80 \%, 70 \%, 50 \%$ by mass corresponding to $\mathrm{Cr}_{3} \mathrm{C}_{2}-20 \% \mathrm{NiCr}, \mathrm{Cr}_{3} \mathrm{C}_{2}-30 \% \mathrm{NiCr}$, and $\mathrm{Cr}_{3} \mathrm{C}_{2}-50 \% \mathrm{NiCr}$, respectively.

Coating equipment: 3710 plasma coating system (PRAXAIR-USA) is uesd.

Coating process: Firstly, a roughing creation is performed on the Shang-Po TM-DT1 abrasive blasting machine using $\mathrm{Al}_{2} \mathrm{O}_{3}$ abrasive with the balsting mode as shown in Table 2 for $\mathrm{Rz}=71 \mu \mathrm{m}$ [9].

Table 2. Sand blasting mode table on tested pieces

\begin{tabular}{|c|c|c|c|}
\hline $\begin{array}{c}\text { Grain size S } \\
(\mathrm{mm})\end{array}$ & $\begin{array}{c}\text { Spraying air } \\
\text { pressure } \mathrm{P}_{\mathrm{p}}(\text { Bar })\end{array}$ & $\begin{array}{c}\text { Spray } \\
\text { distance } \mathrm{L}_{\mathrm{p}} \\
(\mathrm{mm})\end{array}$ & $\begin{array}{c}\text { Spraying } \\
\text { time t (s) }\end{array}$ \\
\hline $0,35 \div 1,19$ & 6.0 & 80 & 30 \\
\hline
\end{tabular}

After roughening, the sample was coated by $\mathrm{Cr}_{3} \mathrm{C}_{2}-\mathrm{NiCr}$ of different carbide content showed in above. Coating technology parameters are made according to Table 3 . The number of coated samples is 9 samples, including 3 samples coated with $\mathrm{Cr}_{3} \mathrm{C}_{2}-20 \% \mathrm{NiCr}, 3$ samples coated with $\mathrm{Cr}_{3} \mathrm{C}_{2}-30 \% \mathrm{NiCr}$; and 3 samples coated with $\mathrm{Cr}_{3} \mathrm{C}_{2}-$ $50 \% \mathrm{NiCr}$. Coating thickness of about $1 \mathrm{~mm}$ for all samples.

Table 3. Specification of coating technology

\begin{tabular}{|l|l|l|}
\hline NO. & MODE & PARAMETER \\
\hline 1 & Current (Ip) & $550(\mathrm{~A})$ \\
\hline 2 & Voltage $(\mathrm{Up})$ & $35(\mathrm{~V})$ \\
\hline 3 & Main air flow $\left(P_{\mathrm{Ar}}\right)$ & $50(\mathrm{l} /$ minute $)$ \\
\hline 4 & Secondary airflow $\left(P_{\mathrm{H} 2}\right)$ & $5(\mathrm{l} /$ minute $)$ \\
\hline 5 & Powdered air flow $\left(P_{\mathrm{Ar}}\right)$ & $40(\mathrm{l} / \mathrm{minute})$ \\
\hline 6 & Spray distance $\left(l_{p}\right)$ & $120 \mathrm{~mm}$ \\
\hline 7 & Flour feeding level $\left(m_{b}\right)$ & $20(\mathrm{~g} /$ minute $)$ \\
\hline 8 & Spray angle & $90^{0} \pm 5^{0}$ \\
\hline
\end{tabular}

\subsection{Evaluation of Coating Properties}

Adhesion measurement: Adhesion of the coating through the sample is measured on the Bestutm 500HH-MS compression machine. The measurement principle is shown in Figure 2.

To ensure measurement results, the sample is manufactured with the following requirements:

- Pegs and latch discs must be perpendicular and concentric when assembled.

- Latch surface and disc when assembled must be tight and coplanar. 
- The latch hole on the latch is machined to ensure the correct center.
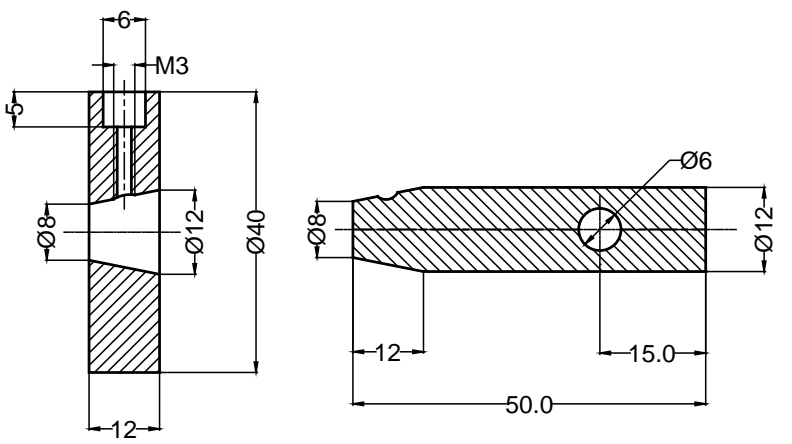

Figure 2. Principle diagram of adhesion evaluation

Based on the structure of the tensile sample, to ensure the concentricity during the tensile process, we designed and made the jig as shown in Figure 3.

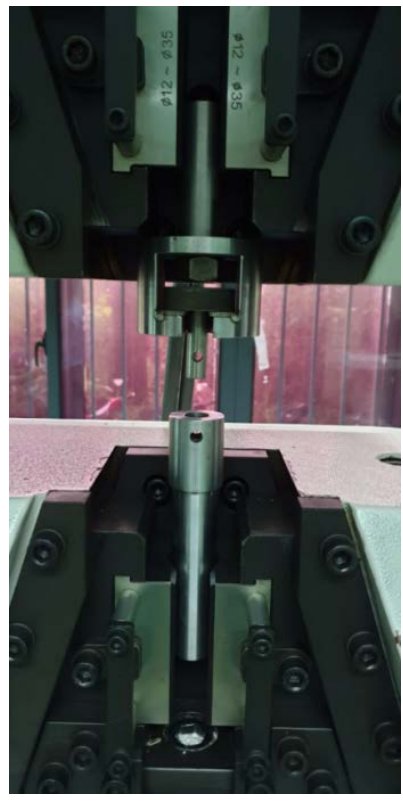

(a)

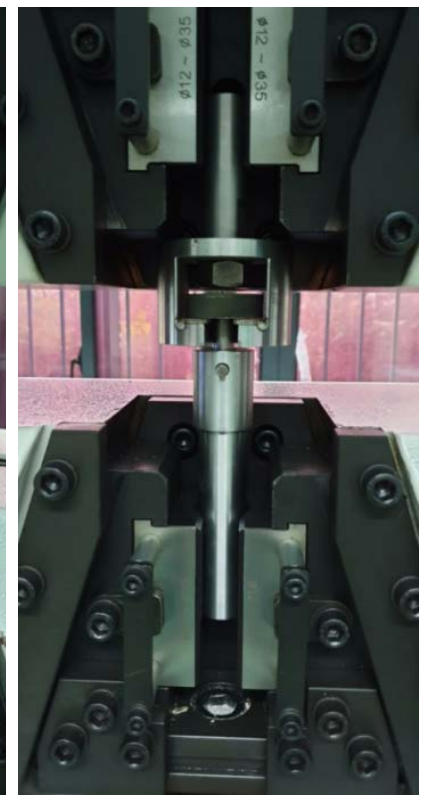

(b)
Figure 3. Image of the sample mounted on the jig

To perform the adhesion measurement $(\mathrm{K})$, the jig is clamped tightly on the clamping jaws of the compressor, then the sample is removed from the fixing screw prior to spraying so that the latch and the latch disc are not affected during roughening and coating. Place the tensile sample in the upper positioning groove of the jig and push the tensile latch closer to the end of the jig positioning groove, which will ensure the concentricity between the upper half of the jig and the lower hilt as shown in Figure 3a. Next, control the mobile head of the machine to translate up so that the latch hole of the tensile sample and the latch hole of the lower half hilt overlap to fasten the pin as shown in Figure 3b. Control the tractor to pull the latch from the latch disc. When the latch is pulled from the disc and the coating is not destroyed on the sample surface, the result is the traction that reflects the adhesion strength of the coating with metal substrate.

Coating microscopic hardness measurement: In this article, we used Vickers method - HV scale on Duramin 2 microscopic hardness tester.

To determine the micro-hardness of the coating, the sample is cut to observe the cross section. After that, it is polished without any scratches on the surface, ensuring technical requirements. Use Duramin 2 microscopic hardness tester by Vickers hardness measuring method $[8,10]$. The measurement process is carried out in accordance with ASTM E384 standard with a loading range of $10 \mathrm{~g} \div 100 \mathrm{~g}$ : The sample is fixed on the sample jig to ensure the flatness, helping the measurement process to be accurate. Through the lens, determine the location to be measured, adjust the specifications on the touch screen. Standard size 4-prong diamond test tip, with the angle between opposite planes $1360( \pm 30)$ will automatically move into position, lower and press the surface of the sample with a load of $100 \mathrm{~g}$ and the load holding time of $10 \mathrm{~s}$. After cutting off the load, measure the diagonal lengths $d$ of the dent.

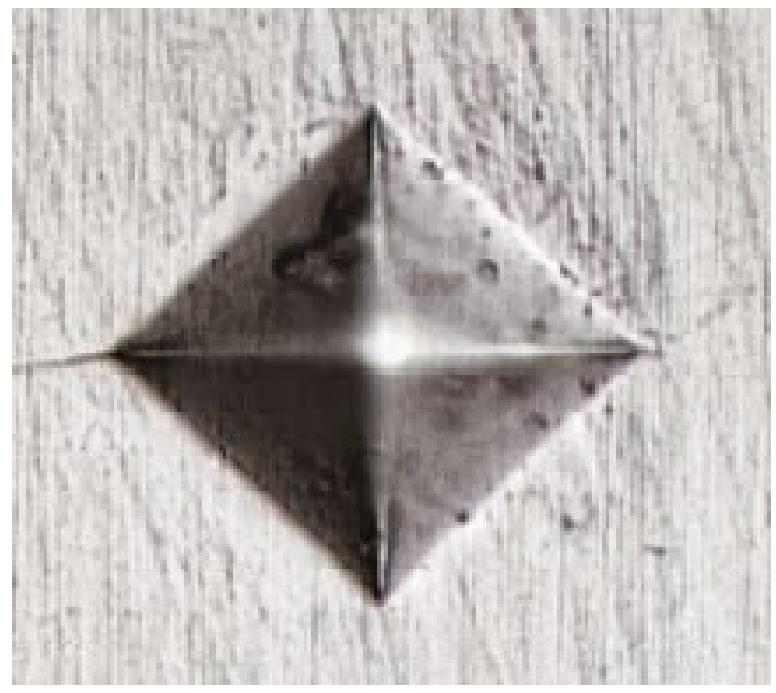

Figure 4. Image of Vickers trace shape

Vickers hardness is calculated by F/S. Take the test force $F$ divided by the area of the concave surface $S$. The concave surface $S$ is calculated as the average of the two diagonal lengths (d1, d2). A concave surface is formed when a force is applied to the sample with a diamond, pyramid-shaped puncture. The angle between two opposite faces with the same vertex is shown in Figure 4. 


\section{Results and Discussion}

\subsection{Effect of the Proportion of Component Coating Material on K Coating Adhesion Strength}

The result of measuring the adhesion $\mathrm{K}$ of the coating to the metal substrate is determined when the latch is pulled off the latch disc as shown in Figure 5. For each percentage of carbide, the adhesion $\mathrm{K}$ is averaged by 3 measurements and results of 3 types of carbide percentage are shown in Figure 6.

Looking at Figure 6, it is easy to see that when increasing the carbide content from $50 \%$ to $80 \%$ by mass, the adhesion of the coating decreases by almost 3 times, from 43.58 MPa to 16.32 MPa. Experimental results show that the composition of $\mathrm{NiCr}$ alloy in the $\mathrm{Cr}_{3} \mathrm{C}_{2}-\mathrm{NiCr}$ coating material has the role of increasing the adhesion between the particles of the coating component, as well as between the coating and the metal substrate. This is in accordance with the theory of materials.

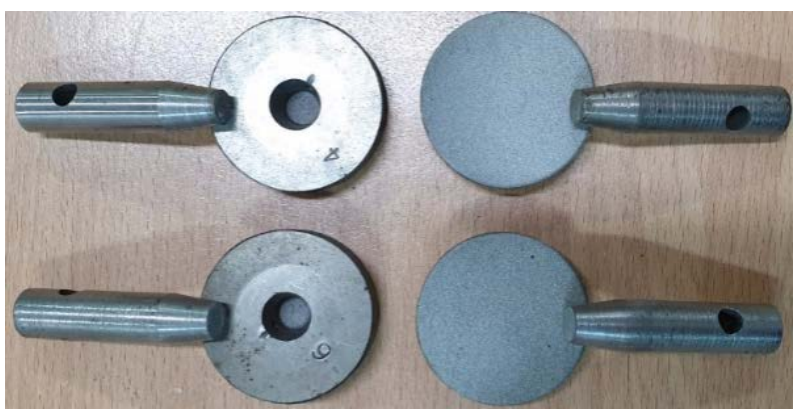

Figure 5. Image of the sample after pulling off the latch

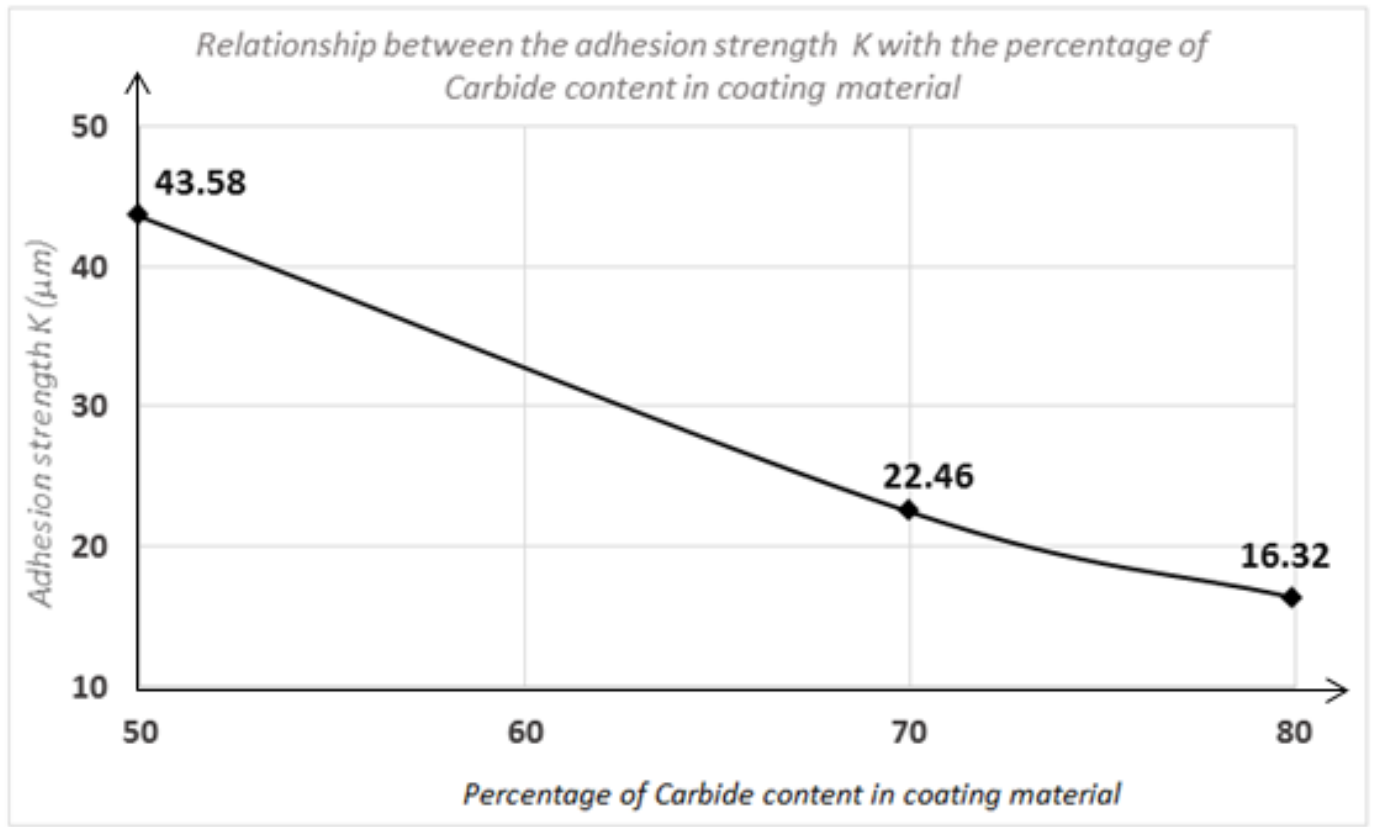

Figure 6. Experimental graph showing the relationship between the adhesion strength $\mathrm{K}$ and the percentage of carbide content in coating material 


\subsection{Effect of the Composition Of Coating Material on HV Hardness of Coating}

HV hardness measurement of the coating is averaged over 3 measurements on 3 samples, each sample is measured in 3 different positions Figure 7. The coating hardness corresponding to each percentage of the carbide content in coating material is shown in Figure 8.
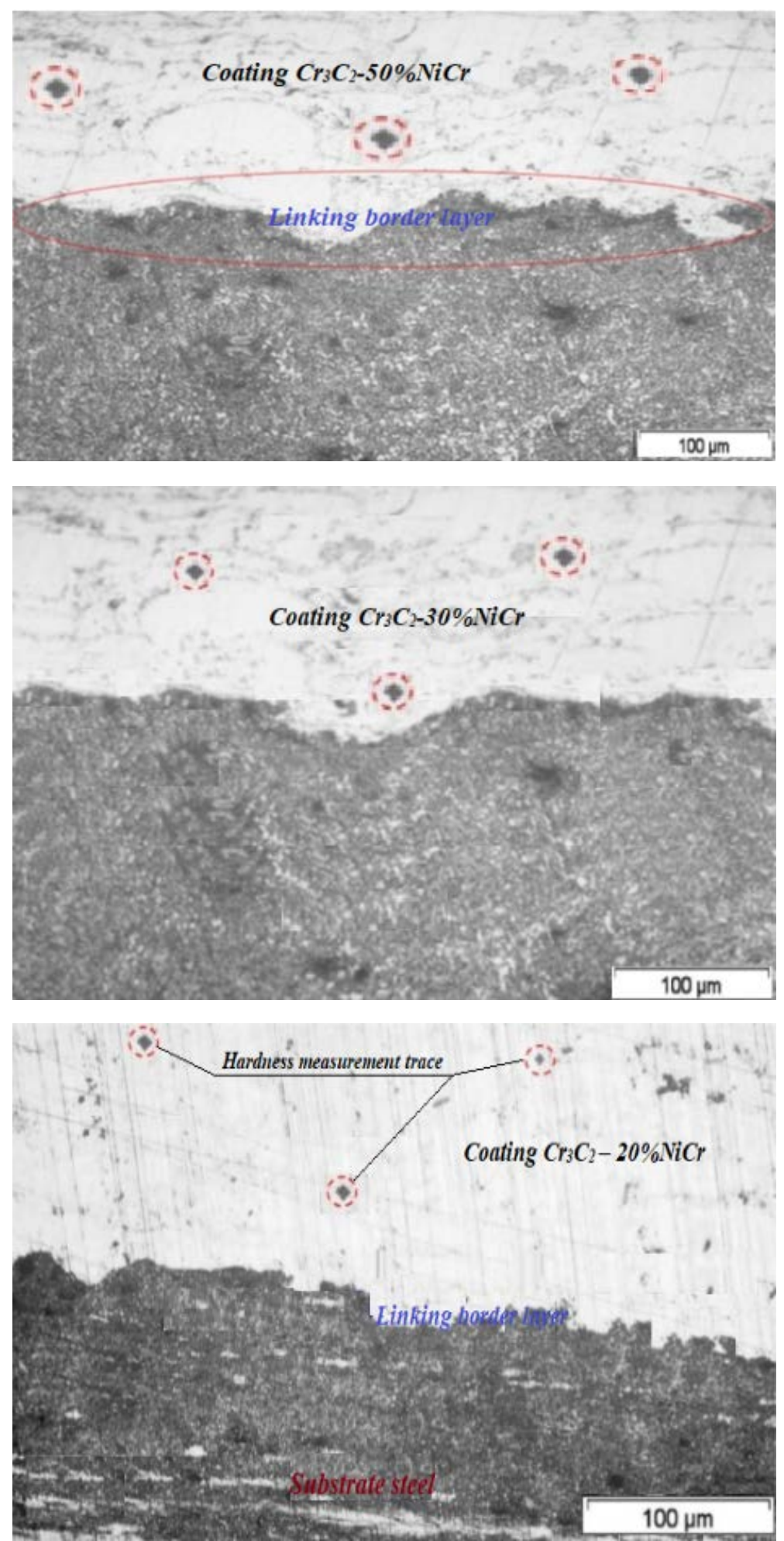

Figure 7. Images show the hardness measurement on $\mathrm{Cr}_{3} \mathrm{C}_{2}-\mathrm{NiCr}$ coatings of 3 carbide contents 


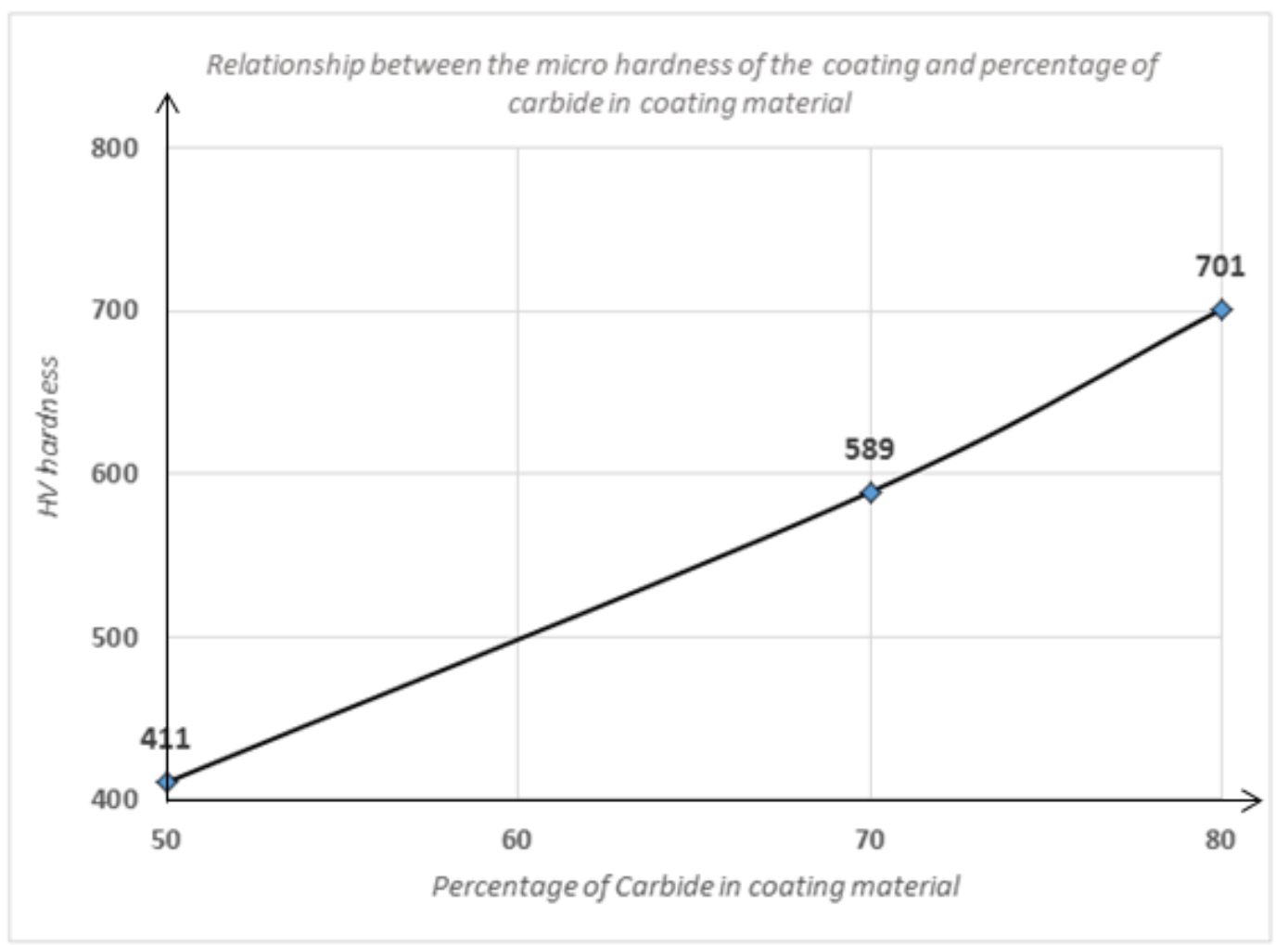

Figure 8. Experimental graph showing the relationship between micro-hardness and percentage of carbide content in coating material

Looking at the graph in Figure 8, it is easy to see that the micro-hardness of the $\mathrm{Cr}_{3} \mathrm{C}_{2}-\mathrm{NiCr}$ coating increases when the carbide content increases from $50 \%$ to $80 \%$ by mass. The hardness of the coating increases by approximately 2 times, from $411 \mathrm{HV}$ to $701 \mathrm{HV}$. In addition, by observing the punctures through the optical microscope Figure 7, it is easy to see that the puncture size increases as the percentage of carbide in the coating material decreases. This can explain by the fact that the $\mathrm{Cr}_{3} \mathrm{C}_{2}$ carbide particles have very high stiffness. When increasing the percentage of the $\mathrm{Cr}_{3} \mathrm{C}_{2}$ carbide in the coating mixtured material, it increases the microscopic hardness of the $\mathrm{Cr}_{3} \mathrm{C}_{2}-\mathrm{NiCr}$ coating.

\section{Conclusions}

The article empirically investigates the effect of the percentage of $\mathrm{Cr}_{3} \mathrm{C}_{2}$ carbide content in the mixture of $\mathrm{Cr}_{3} \mathrm{C}_{2}$ and $\mathrm{NiCr}$ powder on the adhesion of the $\mathrm{Cr}_{3} \mathrm{C}_{2}-\mathrm{NiCr}$ coating to the $16 \mathrm{Mn}$ steel substrate and the microscopic hardness of the coating. Through empirical results, it can be concluded that the composition of $\mathrm{Cr}_{3} \mathrm{C}_{2}$ carbide has a great influence on the adhesion and microscopic hardness of the $\mathrm{Cr}_{3} \mathrm{C}_{2}-\mathrm{NiCr}$ coating on the $16 \mathrm{Mn}$ steel substrate.

Adhesion of $\mathrm{Cr}_{3} \mathrm{C}_{2}-\mathrm{NiCr}$ coating to $16 \mathrm{Mn}$ steel substrate is decreased as the proportion of carbide in the material is increased. The adhesion of the coating containing of $50 \%$ $\mathrm{Cr}_{3} \mathrm{C}_{2}, 70 \% \mathrm{Cr}_{3} \mathrm{C}_{2}$, and $80 \% \mathrm{Cr}_{3} \mathrm{C}_{2}$ is $43.58 \mathrm{Mpa}, 22.46$ Mpa, and $16.32 \mathrm{Mpa}$, respectively.
On the contrary, the hardness of the $\mathrm{Cr}_{3} \mathrm{C}_{2}$ - $\mathrm{NiCr}$ coating on the $16 \mathrm{Mn}$ steel substrate is increased with the increase of the carbide composition in the coating material. With $50 \% \mathrm{Cr}_{3} \mathrm{C}_{2}$ carbide component, the micro-hardness of $\mathrm{Cr}_{3} \mathrm{C}_{2}-\mathrm{NiCr}$ coating is $411 \mathrm{Hv}$; whereas with $\mathrm{Cr}_{3} \mathrm{C}_{2}$ carbide component of $70 \%$ and $80 \%$, the micro-hardness of $\mathrm{Cr}_{3} \mathrm{C}_{2}-\mathrm{NiCr}$ is about $589 \mathrm{Hv}$ and $701 \mathrm{Hv}$, respectively.

\section{REFERENCES}

[1] Magdy M. El Rayes, Hany S. Abdo, and Khalil Abdelrazek Khalil. Erosion - Corrosion of Cermet Coating, Int. J. Electrochem. Sci, 8, 1117 - 1137, 2013.

[2] N. Espallargas, J. Berget., J.M. Guilemany, A.V. Benedetti, P.H. Suegama. $\mathrm{Cr}_{3} \mathrm{C}_{2}-\mathrm{NiCr}$ and $\mathrm{WC}-\mathrm{Ni}$ thermal spray coatings as alternatives to hard chromium for erosion corrosion resistance, Surface and Coatings Technology, 202, 1405-1417, 2008.

[3] P.H. Suegama, C.S. Fugivara, A.V. Benedetti, J.M. Guilemany, J. Fernández, J. Delgado. The in ence uence of gun transverse speed on electrochemical behaviors of thermally sprayed $\mathrm{Cr}_{3} \mathrm{C}_{2}$-NiCr coatings in $0.5 \mathrm{M} \mathrm{H} 2 \mathrm{SO} 4$ solution, Electrochimica Acta 49, 627-634, 2004.

[4] X.M. Li, Y.Y.Yang, T.M. Shao, Y.S. Jin, G. Barbezat. Impact wear performances of $\mathrm{Cr}_{3} \mathrm{C}_{2}-\mathrm{NiCr}$ coatings by plasma and HVOF spraying, Wear, 202, 208-214, 1997.

[5] J.F. Li, L. Li, C.X. Ding. Thermal diffusivity of plasma-sprayed $\mathrm{Cr}_{3} \mathrm{C}_{2}-\mathrm{NiCr}$ coatings, Iranian Journal of 
Materials Science and Engineering, A394, 229-237, 2005.

[6] Guozhi Xie, Yijun Lu, Ziyi He, Bing Hu, Keyu Wang, Xiangyin Mo, Yuping Wu, Pinghua Lin. Microstructure and corrosion properties of plasma-sprayed $\mathrm{NiCr}-\mathrm{Cr}_{3} \mathrm{C}_{2}$ coatings comparison with different post treatment, Surface \& Coatings Technology, 202, 2885-2890, 2008.

[7] Bhushan B, and Gupta B K. Handbook of Tribology Material Coating and Surface Treatments, McGraw-Hill, New York, (1991).

[8] Pierre L. Fauchais, Joachim V.R. Heberlein, Maher I. Boulos (2014), Thermal Spray Fundamentals, Springer.

[9] Dang Xuan Thao; Hoang Van Got; Pham Duc Cuong. "Research on Effects of Blasting Distance and Pressure To Surface Roughness of $16 \mathrm{Mn}$ Alloy Steel when Blasting Using Blasting Machine;Journal of science \& Tachnology Hanoi University of Industry,53, 2019, pp. 44-47.

[10] Pham Van Lieu. "Evaluating the Effects Of Technological Parameters On The Quality Of Surface Restoration Of Abrased Complex Shafts With Spraying -Coating Technology". PhD thesis, University of Mining and Geology, 2016. 